\title{
THE PERSISTENT OSTIUM PRIMUM ATRIAL SEPTAL DEFECT (Partial Persistent Common Atrioventricular Canal)
}

\author{
T. Holmes Sellors, D.M., M.CH., F.R.C.S. \\ Thoracic Surgeon, Middlesex Hospital; Surgeon, National Heart Hospital, London Chest Hospital, \\ Harefield Hospital \\ Walter Somerville, M.D., F.R.C.P. \\ Physician, Department of Cardiology, Middlesex Hospital; Cardiologist, Harefield Hospital
}

\section{Anatomy}

THE embryological development of the mitral and tricuspid valves is intimately related to the formation of the adjacent portions of the atrial and ventricular septa. The clinical condition known as the complete form of the persistent common atrioventricular canal represents an arrest in development of these four structures, the two valves and the two septa. When a heart with this condition is laid open, a continuous defect can be seen involving the lowermost portion of the atrial septum and the uppermost part of the ventricular septum. A single atrioventricular valve lies across this defect representing the mitral and tricuspid valves whose development ceased before they were evolved into two separate structures each attached to its own individual valve ring. The valve is composed of two large leaflets, anterior and posterior with smaller lateral leaflets. Two lateral leaflets lie on the right side, the anterior and posterior leaflets of the tricuspid valve, and a single lateral leaflet on the left, the posterior cusp of the mitral valve. This, the complete form of the persistent common atrioventricular canal, is relatively rare.

Partial forms of the condition are more common and the best known of these is the persistent ostium primum about which this paper is concerned. Apart from its interest to anatomists, its importance lies in the fact that it offers a hopeful prospect for surgical correction.

The lower boundary of the persistent ostium primum is the atrioventricular valves, in contrast to the ostium secundum defect which has a lower rim, however narrow, separating it from the valves. This is the single most important distinguishing anatomical feature between these two types of atrial septal defect. The mitral valve is almost invariably deformed by a cleft in the anterior leaflet. Accessory chordæ tendineæ attached to the cleft leaflet may contribute to the incom- petence of the valve (Edwards, 1960). The trif cuspid valve is usually normal, but uncommonts its septal leaflet is cleft too. When both mitral and tricuspid valves are malformed in this way, $\mathcal{G}_{\mathrm{G}}$ careful search will usually disclose a small ven tricular septal defect of the appropriate typ designating the condition as a complete rather than a partial common atrioventricular cana魚 Ostium primum defects of all sizes have been seen from a few millimetres across to the situanofon when no trace of an atrial septum exists, thescen triloculare biventriculare or common atrium (F Kirklin, Swan, DuShane and Edwards, 1959)..+

In addition to the persistent ostium primum and the common atrium, a wide variety exists partial forms of the common atrioventricular can depending on the degree of development of eac\$ of the four components of the canal. Some of these are very uncommon and might be classed as collectors' pieces, for instance an isolated clef mitral or tricuspid valve or both, an isolated ostium primum with normal valves (Bloun Balchum and Gensini, 1956), an isolated defect of the upper part of the ventricular septum 을. permutations of these anomalies (Kiely, Adams, Anderson and Lester, 1958). In the isolated cle mitral valve, the anterior or aortic cusp is cleff the posterior cusp and the tricuspid valve are normal and the septa intact (Edwards, Dro Parker, Burchell, Wood and Bulbulian, 1954: The anatomical, electrocardiographic and vectoos cardiographic distinction between the isolaterd ventricular septal defect forming part of the common atrioventricular canal and the usual type of ventricular septal defect have been defined by the Mayo Clinic workers (Neufeld, Titu命 DuShane, Burchell and Edwards, 196I). The remainder of this paper deals with the ostium primum defect with which is implied a cleq mitral valve. 


\section{Diagnosis}

It has been our practice to repair all atrial septal defects (ASD) under direct vision by openheart surgery, the ostium secundum defects under hypothermia and the ostium primum defects using extra-corporeal circulation. The pre-operative recognition of the type of defect present is therefore essential. The operable ostium primum defect in our experience is about seven times less common than the operable ostium secundum defect. Each of the following six diagnostic procedures contributes something to the identification of the persistent ostium primum, but experience has whittled down their number to two crucial tests-auscultation, and the electrocardiogram and vectorcardiogram considered together. The other four, the chest radiogram, cardiac catheterization, dye dilution curves and angiocardiography are less specific and less reliable.

Auscultation. An ejection-type systolic murmur followed by clear splitting of the second sound is heard in the pulmonary area. By splitting of the second sound is meant the audible closure of the aortic valve (A2), followed by closure of the pulmonary valve $\left(\mathrm{P}_{2}\right)$. The interval between these two elements of the second sound may be constant in inspiration and expiration-' fixed splitting 'or it may be longer during inspiration and shorter during expiration. This pair of signs, the murmur and the splitting of the second sound, is common to both types of atrial septal defect. In the ostium primum defect, a separate mitral systolic murmur is usually heard at the apex, different in pitch and occupying the whole of systole (pan-systolic). These murmurs are illustrated in Fig. 1 . The murmur at the pulmonary area is produced by the ejection of blood from the right ventricle into the pulmonary artery. The mitral pan-systolic murmur is caused by regurgitation of blood from the left ventricle to the left atrium through the deformed and incompetent mitral valve. A similar type of pan-systolic murmur is sometimes heard at the tricuspid area denoting tricuspid regurgitation. Identification of the two different pansystolic murmurs is not always possible by stethoscope or phonocardiogram. Loudening of the murmur during inspiration and waning during expiration used to be thought typical of tricuspid murmurs, but has not stood the test of experience; many systolic murmurs which behaved in this way were found at operation to come from the mitral valve, the tricuspid valve being normal. A tricuspid diastolic murmur becoming louder in inspiration is heard when a large shunt exists between the left and right atria. Occasionally a separate mitral diastolic murmur is produced by a turbulent blood flow across the deformed mitral valve. Generally, the same difficulty in precise
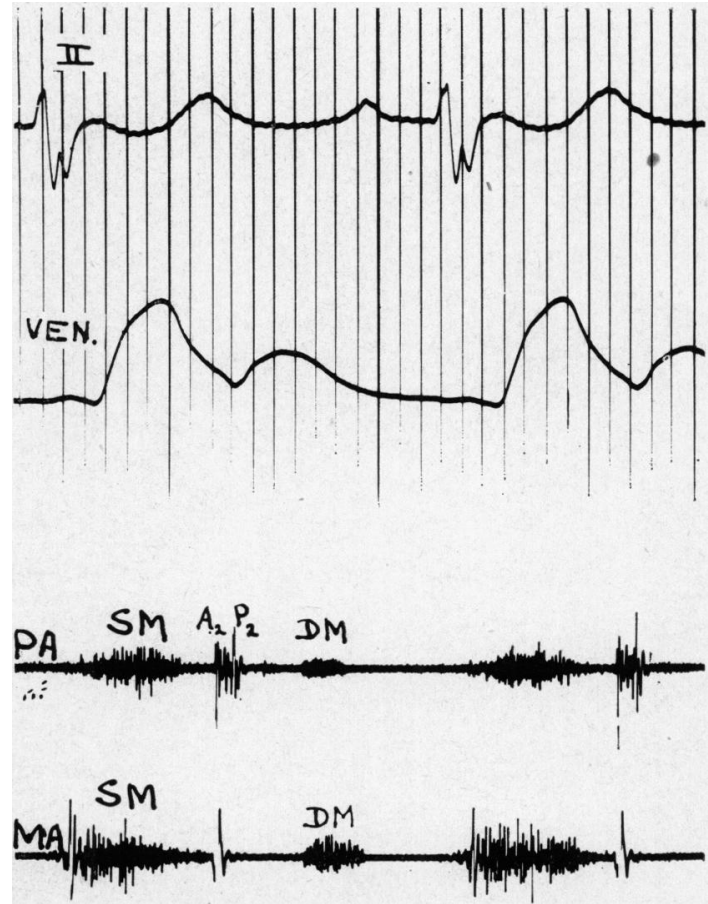

FIG. I.-Phonocardiogram of patient with ostium primum defect. At the pulmonary area (PA) an ejection-type siystolic murmur (SM) is followed by the two components of the second heart sound $\left(A_{2}\right.$ and $\left.P_{2}\right)$. At the mitral area (MA) the systolic murmur (SM) begins at the first heart sound and continues throughout systole. The diastolic murmur (DM) is recorded at both $\mathrm{MA}$ and PA; in this patient it was loudest at the tricuspid area (not shown). ECG lead II and a venous tracing (VEN.) are recorded above.

identification exists for the diastolic as well as the systolic murmurs.

These auscultatory findings hold good for the majority of operable ostium primum defects. Naturally they are modified when the defect is small or the valve nearly normal, but then the clinical diagnosis is not critical from the viewpoint of surgical treatment.

Electrocardiogram and Vectorcardiogram. There are two features of the electrocardiogram (ECG) which together identify an ostium primum defect with near certainty in a person having the auscultatory pattern described above. They are left axis deviation (LAD) and in the chest leads the pattern of right ventricular diastolic overload, sometimes called ' incomplete right bundle branch block'. This pair of signs is shown in Fig. 2 and contrasted with the usual pattern of the ostium secundum defect. Two other ECG signs sufficiently common to have diagnostic value are a notched S wave in lead II (Somerville, 1960) and a PR interval of $0.22 \mathrm{sec}$. or longer. 

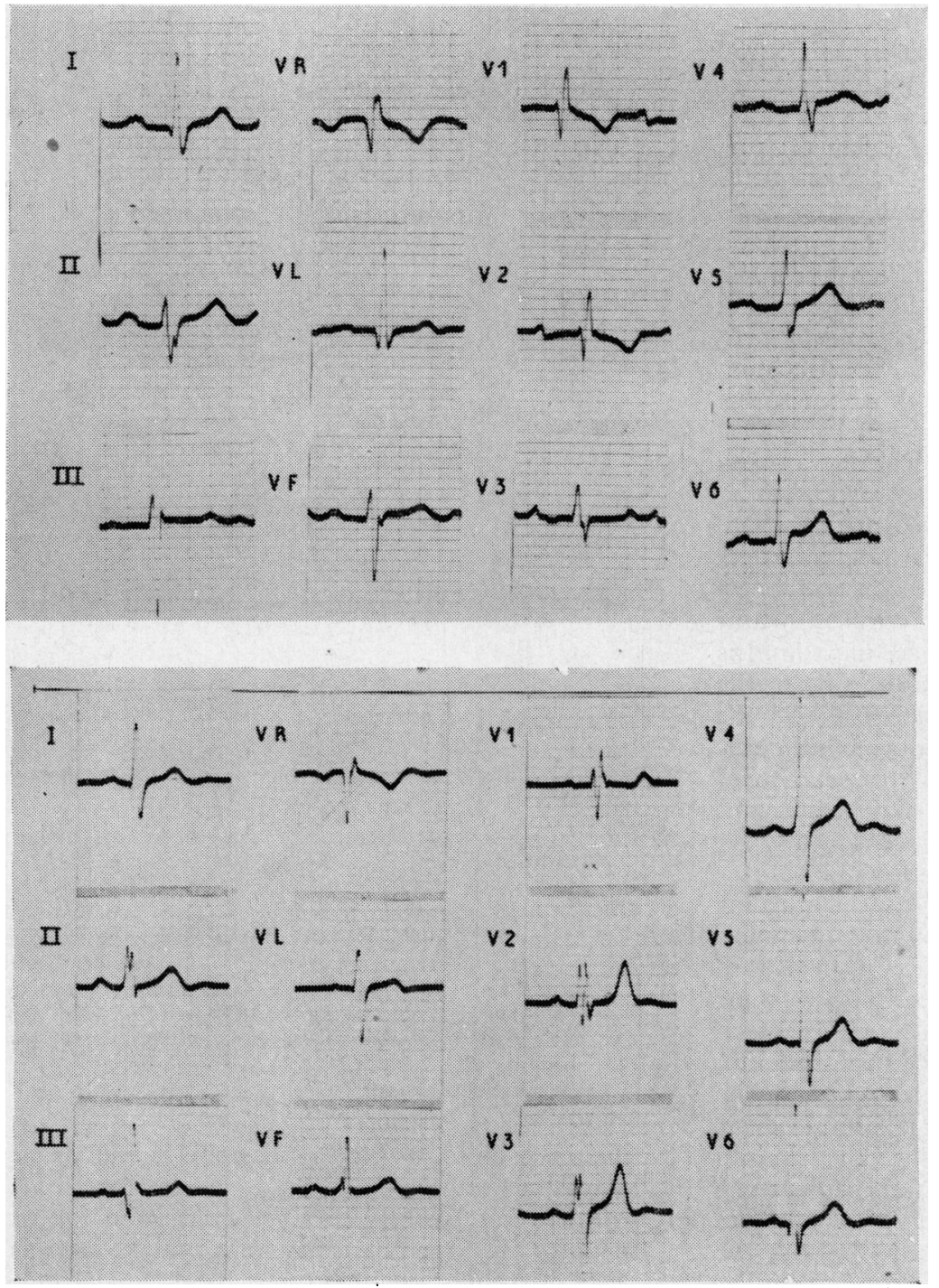

FIG. 2.-ECG of ostium primum ASD (above) and ostigion secundum ASD (below). In both, right ventricular diastolic overload pattern (incomplete right bundle bramch block) is shown in VI-2. The ostium primum graph ${ }_{3}$ is distinguished by left axis deviation, prolonged P-R (o,22 sec.) and a notched $S$ wavein lead II. Time marking: $\Phi .1$ sec.

The frontal vectorcardiogram (VCG) as would be expected from the ECG has a characteristic form in ostium primum defects which distinguishes the primum from the secundum defects (Fig. 3). In ostium primum defects, the loop lies above the isoelectric point and rotates counterclockwise, whereas in ostium secundum defects it lies below the isoelectric point and rotates in a clockwise direction (Toscano-Barbosa, Brandenburg and Burchell, 1956).

We feel justified in relying strongly on the ECG and VCG to identify an ostium primum defect when an ASD is present. Diagnostic patterns were present in both ECG and VCG in over $90 \%$ of our surgically-treated cases of ostium primum defects already reported (Bedford and Sellors,
I960) and in 28 patients operated on since theri A like degree of confidence in these tests has bee stated by the Mayo Clinic workers (DuShanes Weidman, Brandenburg and Kirklin, 1960). A experience of these lesions widened, exceptions to the usual ECG and VCG patterns were noted (Somerville, I96I), but it is unlikely that these will be common enough to take from the diags nostic value of the tests.

Chest Radiogram. The chest radiogram is indiso pensable for the diagnosis of ASD, but there are no consistent diagnostic features distinguishing ostium primum from ostium secundum defects (Fig. 4).

Cardiac Catheterization. A cardiac catheter ca $\stackrel{7}{\bar{\phi}}$ be passed from right to left atrium in the grea⿱⺈ 


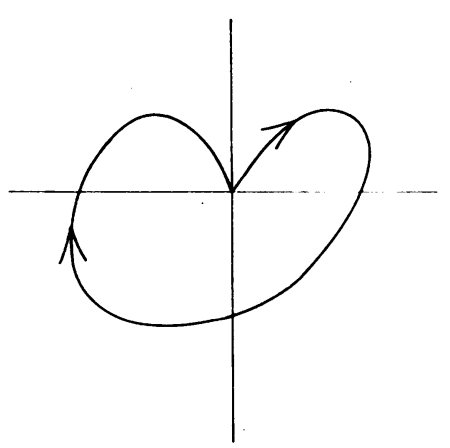

A

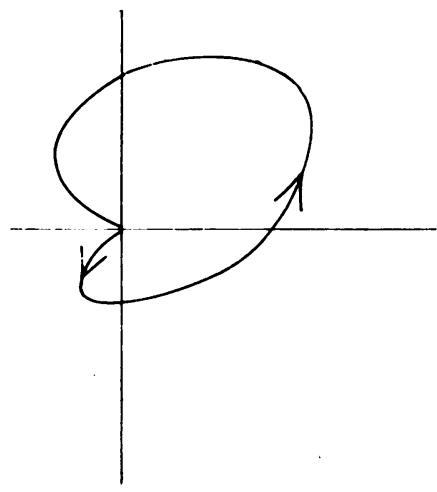

Fig. 3.-Frontal vectorcardiograms (diagrammatic) in ASD. In the ostium secundum defect (A) the loop lies mainly below the isoelectric point and rotates clockwise. In the ostium primum defect (B) it lies mainly above the isoelectric point and rotates counter-clockwise. majority of cases of ASD. When the catheter traverses the ostium primum it lies in close relation to the tricuspid valve or it can be manœuvred into this position. It can pass directly into the left ventricle from the right atrium when the tricuspid valve is cleft. The position of the catheter as it lies in the left ventricle having passed through the cleft mitral valve is fairly characteristic but unfortunately not diagnostic because in certain low ostium secundum defects the catheter can take a similar course.

A pressure tracing in the left atrium may show mitral regurgitation if the catheter tip can be placed in a suitable position. However, the absence of such a pressure pattern has no diagnostic value.

Dye Dilution Curves. In the ostium secundum defect, blood returning from the right lung is shunted preferentially into the right atrium because of the proximity of the right pulmonary vein orifices to the septal defect. Dye dilution curves after injections into left and right pulmonary arteries respectively have characteristically different shapes. In certain ostium primum defects the curves are similar because, as a rule preferential shunting from the right lung does not occur, the orifices of the right pulmonary veins being remote from the defect (Wakai, Swan and Wood, 1956). Naturally this distinction ceases to exist when the ostium primum defect is very large, for instance in its ultimate form, the common atrium, or when a separate ostium secundum defect is present.

In the common atrium or cor triloculare biventriculare, no remnant of atrial septum is present, or it may be represented by a small fringe on a portion of the circumference of a large common atrial chamber. The atrioventricular valves are abnormal as described earlier; one or both may be cleft or a common valve may lie across the atrioventricular space. The diagnostic features of this condition are shown by cardiac catheterization: a shunt from left to right atrium, oxygen saturation in the pulmonary artery equal to or in excess of that in a systemic artery, and dye dilution curves showing a left-to-right shunt across the ASD when the injection is made in the pulmonary artery, and a right-to-left shunt when made in right atrium or superior vena cava (Ellis, Kirklin, Swan, DuShane and Edwards, 1959).

Angiocardiography. Angiocardiograms obtained from injection of contrast medium into right atrium, right ventricle, pulmonary arteries or left atrium have no diagnostic value beyond confirming a shunt from left to right atrium. Left ventricular injection through a catheter passed via a systemic artery may show mitral regurgitation followed by passage of the medium from left to right atrium. In this way an ostium primum defect may be suspected. These findings are not conclusive, however, because they also occur when an ostium secundum defect is associated with organic mitral incompetence, congenital or acquired. A further limitation to this technique is the fact that the cleft mitral valve found with ostium primum defects - and indeed the common atrioventricular valve in complete persistent common atrioventricular canal-cannot always be shown to be incompetent even when the injection and angiocardiographic techniques are flawless.

In summary, the diagnosis of ostium primum defects is made mainly on the following points: (I) By auscultation, when a pan-systolic mitral murmur is present in addition to the usual auscultatory signs of ASD, and (2) from the ECG which shows left axis deviation as well as the pattern of right ventricular diastolic overload (incomplete right bundle branch block) and from the VCG when the frontal loop is mainly above the isoelectric point and rotates counterclockwise. The position of the cardiac catheter as it passes from the right atrium to the left atrium and left 


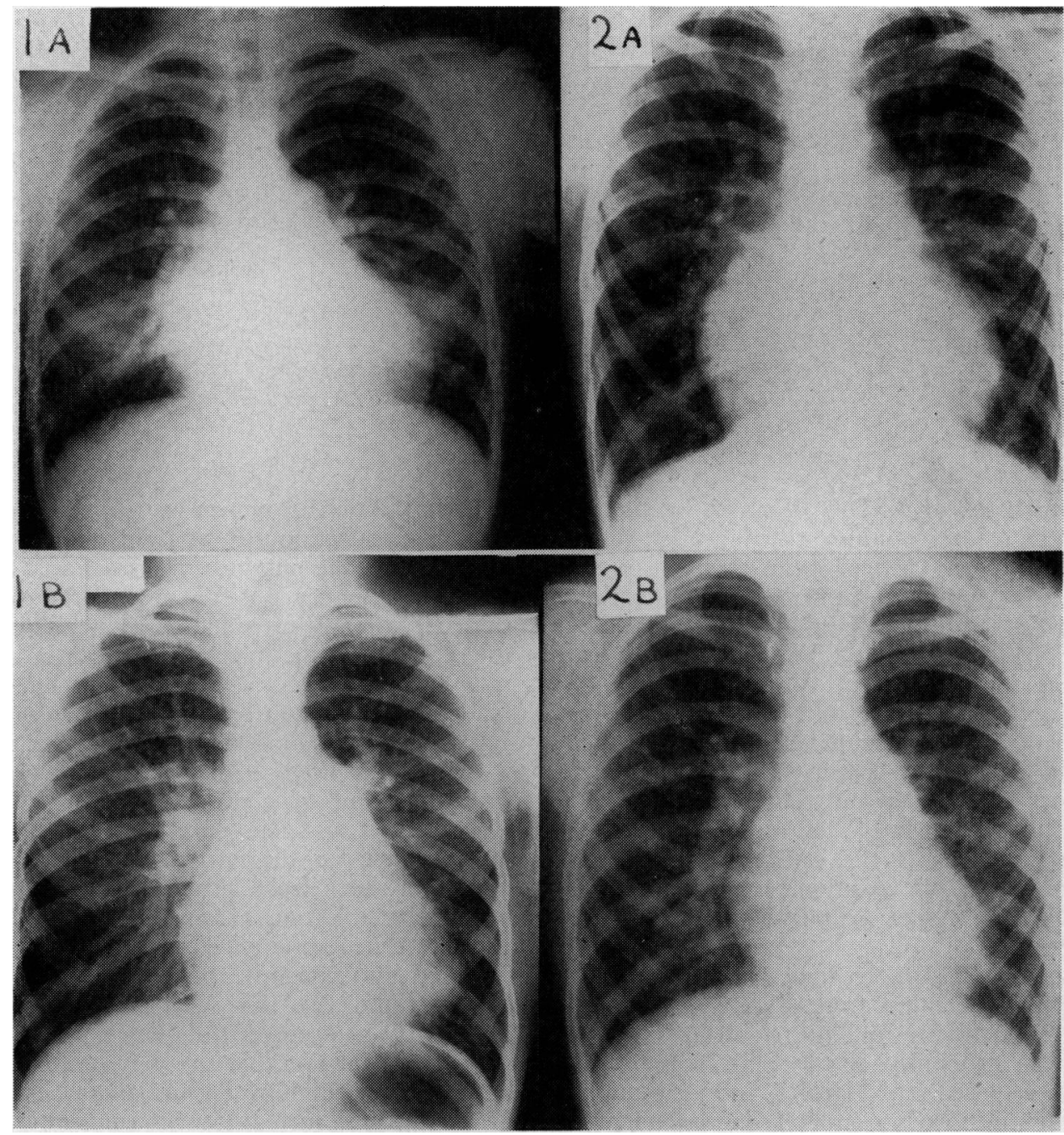

Fig. 4.-Chest radiograms of two patients with ostium primum (IA and IB) and two patients with ostium secundum defects $(2 \mathrm{~A}$ and $2 \mathrm{~B})$ showing the similarity between the two conditions. IA girl aged 12, ostium primum $4.5 \times 2 \mathrm{~cm}$. 2 A girl aged 9, ostium secundum $4 \times 2.5$ $\mathrm{cm}$. IB girl aged 8, ostium primum $3.5 \times 3 \mathrm{~cm}$. $2 \mathrm{~B}$ girl aged 8 , ostium secundum $3.5 \times 3 \mathrm{~cm}$. Pulmonary artery pressure similar in all four patients (18-22/6-10 $\mathrm{mm}$. Hg.).

ventricle, and dye dilution curves are sometimes of diagnostic help.

\section{Selection of Cases for Operation}

When the diagnosis is secure, the decision to proceed to surgical repair is made when the lesions are thought to be serious enough to be a threat eventually to the patient. In our present understanding of the condition, four factors are important: the size of the left to right atrial shunt, the heart size, the pulmonary arteriolar resistance, and the severity of the valve incompetence.

Small shunts from left to right atrium are, of themselves, probably not dangerous, but the size of the shunt should be considered together the degree of mitral incompetence. Our present feeling is that the defect should be repaired when the pulmonary flow has been augmented by the shunt so that it is twice the systemic flow nor greater, measured at rest (that is, the pulmonaty/ systemic ratio is 2 or more). With smalfer shunts, the decision regarding operation must fe made on other grounds. In the absence of pialmonary hypertension the heart size is a rough guide to the combined effects of the shunt amid of the valve incompetence. This means that $a$ 
rule operation is not needed when the heart size is normal (cardiothoracic ratio 45 or less). A high resistance means obstructive pulmonary arteriolar disease and it carries a heavy operative risk. The highest resistance in our series has been 4 units (320 dynes/sec./cm. ${ }^{-5}$ ) and we feel that this figure should be taken as the upper limit of safety. When mitral incompetence dominates the clinical picture, the decision to operate depends on the severity of the mitral lesion. The surgical management of mitral incompetence is described elsewhere (Barnard and Schrire, I96r).

\section{Surgical Treatment}

In correcting ostium primum defects our custom has been to employ full body perfusion at 2.4 litres/sq. metre body surface at normal body temperature, using the Mayo-Gibbon heart-lung machine.

The patient is anæsthetized and placed on the operating table with a needle or cannula in the right external jugular vein. This is attached to a manometer for measuring the venous pressure. Blood pressure and ECG records are also made.

The incision may be vertical, splitting the sternum longitudinally, or transverse with deliberate opening into one or both pleural cavities. Though the vertical incision is currently more popular, we find no difference in the management and after-pain between the vertical and transverse incisions. The transverse approach gives better exposure of the atrium and is therefore preferable in atrial septal defects, whereas the vertical incision is better placed for ventriculotomy.

The incision is enlarged by forceful retraction and absolute hæmostasis ensured before opening the pericardium. Stay sutures to the cut edges of the pericardium serve to act as retractors and to bring the heart towards the surface. The venæ cavæ are dissected and surrounded with tapes which will later act as tourniquets. If pressures are required they are recorded at this stage.

Cannulation of a femoral or external iliac artery may be undertaken at the start of the operation, or at this stage as soon as the patient has been given a dose of heparin. After the cannula has been inserted, attention is given to venous cannulation.

The atrial appendage is lightly clamped and incised prior to digital exploration, after which the venous cannulæ are inserted, directed into the venæ cavæ and secured. The heart-lung machine, which will by this time be primed and circulating, is then connected to the venous and arterial cannulæ and perfusion is started. It is customary to use a period of partial 'by-pass' before tightening the venous tapes and establishing total perfusion.

When perfusion has been satisfactorily established the atrium is incised and blood sucked out through the coronary sinus sucker. The atrial incision is carried up to the venous cannulæ which can then be retracted or adjusted while the atrial interior is inspected.

The appearance of ostium primum defects is remarkably constant. A well-defined crescentic edge marks the upper limit of the septum and below this are the poorly demarcated tricuspid and mitral valve cusps. The upper edge of the ventricular septum is usually only recognized on palpation. It appears as if two delicate veils of cusp are laid over the ventricular septum and the line between them is roughened or nodular. The mitral valve is always cleft and if the tricuspid is likewise deformed, the ventricular septal edge will be visible. The cusps themselves may not be attached to the septum, but in all cases there is an obvious abnormality of the chordal attachments and rotation of the aortic cusp of the mitral.

The strong probability of regurgitation makes it imperative to close enough of the cleft mitral valve to prevent gross reflux, but this repair or closure must not be carried too far lest the mitral orifice be unduly narrowed. Usually four to five closely placed thread stitches afford a satisfactory repair. Abnormal chordal attachments keeping the valve open during systole must be identified and divided, and if the heart has not been subjected to artificial arrest, the competence of the valve can be tested. A similar repair of the tricuspid valve should be carried out if this valve is cleft.

Before starting closure of the defect itself it must be ensured that the valves are firmly attached to the upper part of the septum.

The defect extends the whole width of the atrioventricular ring blending off at the upper margin over the aortic sinuses and to the left of the coronary sinus below to join the crescentic upper margin. The average short axis of the defect is 1.5 to $2 \mathrm{~cm}$., which is too great for direct suture. In some early cases in which the distance was less than $1.5 \mathrm{~cm}$. direct suture was used, but certainly in two cases there was a partial disruption at a later date. In consequence, and in spite of inherent objections to buried forcign material, a prosthesis has to be used. This originally consisted of compressed Ivalon, but has been succeeded by the more fashionable Teflon felt.

The first sutures are placed through the cusps into the top of the ventricular septum deep enough to obtain a firm hold but placed in the 
long axis to avoid possible injury to the conducting tissue. Three or four sutures will suffice to form the base for the patch which is sewn on so as to close the defect. At the upper border sutures must be placed superficially to avoid damage to the aorta, and at the lower border where the atrioventricular node lies between the defect and the coronary sinus. The ECG is carefully watched for any sign of heart block. Should it occur when inserting or tying a suture in this region the stitch must be removed immediately. A hæmatoma or œdema may lead to continued block, but it should not be permanent so long as the anatomical integrity of the node and bundle has been maintained. When the patch is complete the atrial incision is closed, taking care to exclude air before final closure round the venous cannulæ. Perfusion is then stopped and when the heart has taken over with good action the cannulæ are removed and the action of heparin is neutralized by an appropriate dose of polybrene.

If there is any question of heart block, two (or three) electrodes are sutured into the anterior wall of the right ventricle and passed through stab incisions in the skin. These are connected to a pace-maker which can be used if required.

The wound is closed after further attention to hæmostasis and the pericardium and pleural cavities (if opened) are adequately drained by suction tubes.

The complications of the operation are firstly those of perfusion. Bleeding from coagulation failure or from the actual heart incision and electrolyte disturbance from inadequate perfusion are possibilities. The complications referable to the intracardiac procedures are firstly disorders in the conduction mechanism, for example, he block and arrhythmias. Permanent damage to the node or bundle is irreversible, but temporary heart block due to a hæmatoma or traction in the region of these delicate structures is usually coptrolled by isoprenalin or by pace-making over-a period of two or three weeks. Bacterial end carditis may result from the embedding of $\bar{\Phi}$ a foreign body (patch) in the heart.

The repair of the deformed valve may rot leave a perfectly functioning structure and the risk of producing mitral stenosis has been menttioned. There may also be some measure residual mitral incompetence if a perfectly closigg valve cannot be constructed.

\section{Summary}

The persistent ostium primum atrial septs defect is a defect in the lowermost portion of the atrial septum. A cleft mitral valve and abnornal chordæ tendineæ are usually present.

When an atrial septal defect has been confirmed by the usual techniques, an ostium primu而 defect is recognized from auscultation, the electifcardiogram and vector cardiogram.

Selection for surgical correction is based on the size of the shunt from left to right atrium, of heart size, the pulmonary arteriolar resistine, and the degree of valve incompetence.

Surgical correction consists of closure of the defect by a prosthesis and repair of the deformed mitral valve under extra-corporeal circulation.

We are indebted to Dr. Evan Bedford and the steff of the Departments of Thoracic Surgery and Cardiology, Middlesex Hospital, and of the National Heart, Londgn Chest and Harefield Hospitals.

\section{REFERENCES}

Barnard, C. N., and Schrire, V. (1961): Surgery of Mitral Incompetence, Postgrad. med. F., 37, 666.

BEDFord, D. E., and Sellors, T. H. (1960): The Atrio-Ventricular Type of Atrial Septal Defect and its Surgiceal Treatment, Brit. Heart $\mathcal{F}$., 22, 300.

Blount, S. G., Balchum, O. J., and Gensini, G. (1956): The Persistent Ostium Primum Atrial Septal Defect, Circulation, 13, 499.

DuShane, J. W., Weidman, W. H., Brandenburg, R. O., and Kirklin, J. W. (1960): Differentiation of Interatigal Communications by Clinical Methods, Ibid., 2I, 363 .

EDwards, J. E. (1960): The Problem of Mitral Insufficiency Caused by Accessory Chordæ Tendineæ in Persisteint Common Atrioventricular Canal, Proc. Mayo Clin., 35, 299.

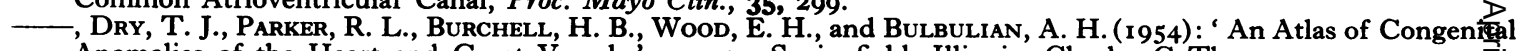
Anomalies of the Heart and Great Vessels', p. 35. Springfield, Illinois: Charles C Thomas.

Ellis, F. H., Kirklin, J. W., Swan, H. J. C., DuShane, J. W., and EDWARDS, J. E. (1959): Diagnosis and Surgifol 1 Treatment of Common Atrium (Cor Triloculare-biventriculare), Surgery, 45, 160.

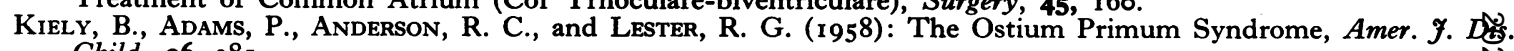
Child., 96, 381.

Neufeld, H. N., Titus, J. L., DuShane, J. W., Burchell, H. B., and Edwards, J. E. (196r): Isolated Ventricular Septal Defect of the Persistent Common Atrioventricular Canal Type, Circulation, 23, 685.

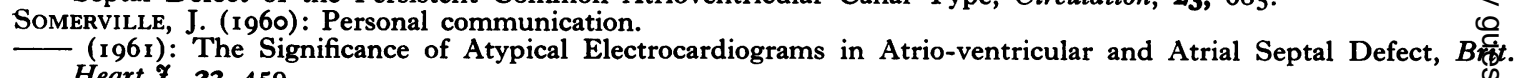
Heart $\mathcal{Y}$., 23, 459 .

Toscano-Barbosa, E., Brandenburg, R. O., and Burchell, H. B. (1956): Electrocardiographic Studies of Cases with Intracardiac Malformations of the Atrioventricular Canal, Proc. Mayo Clin., 3I, 5 I 3.

WakaI, C. S., Swan, H. J. C., and Wood, E. H. (1956): Hemodynamic Data and Findings of Diagnostic Value $\mathrm{乃}^{\mathrm{n}}$ Nine Proved Cases of Persistent Common Atrioventricular Canal, Ibid., 3I, 500. 